\title{
POST ANAESTHETIC RECOVERY FOLLOWING DAY-CARE SURGERY: COMPARISON OF TWO ANAESTHETIC TECHNIQUES
}

\author{
Dhrubajyoti Borgohain ${ }^{1}$, Rajib Bhattacharyya2 , Jyotishmoy Bora ${ }^{3}$ \\ ${ }_{1}^{1}$ Assistant Professor, Department of Anaesthesiology, Assam Medical College \& Hospital, Dibrugarh, Assam. \\ 2 Professor, Department of Anaesthesiology, Jorhat Medical College \& Hospital, Assam. \\ ${ }^{3}$ Post Graduate Trainee, Department of Anaesthesiology, Assam Medical College, Dibrugarh.
}

\section{ABSTRACT}

\section{BACKGROUND}

The growing demand for early discharge from hospital, consequent early return to work has resulted in the evolution of concept of "day care surgery." This has led to development of precise safe anaesthetic techniques and agents as well as a battery of tests of recovery. Day care surgery presents unique challenges for the anaesthetists to produce a 'street fit' patient as soon as possible after the surgery with least complications, which can be achieved by both intravenous and inhalational techniques. Thus, an endeavour was made to carry out the present study with the aims and objectives to assess the progress of recovery in patients undergoing day care surgery with two groups of intravenous anaesthetic agents and also to determine the optimum time taken to achieve "home readiness."

\section{METHODS}

The study included patients of average intelligence of both sexes aged between 15 and 45 yrs. belonging to physical status ASA I and II, undergoing operative procedures less than 30 minutes in our institute over a period of two years. A randomized double blind study was done amongst 80 patients scheduled for day care surgery, where two techniques were compared. Amongst 2 groups [Group I: Propofol (1\%) and Group II: Thiopentone (2.5\%) as the intravenous anaesthetic agent]. Recovery was assessed using standard scoring systems. The different variables were evaluated by mean and standard deviation. For comparing two groups, paired ' $\mathrm{t}$ ' test was applied and a $\mathrm{p}$ value of $<0.05$ was considered significant.

\section{RESULTS}

The mean total dose requirement in Group-II patients were more than that in Group-I patients ( $\mathrm{p}<0.001)$. When comparing the induction time in both the study groups, no statically significant difference was noted ( $p>0.05$ ), but the quality of anaesthesia was excellent in $57.5 \%$ in Group-I as compared to $45 \%$ in Group-II. After 5 minutes of cessation of anaesthesia, patients in Group-I attained much higher score as compared to Group-II $(\mathrm{p}<0.001)$ as assessed by the "Steward scoring system." More number of patients were "Home ready" in Group-I than in Group-II ( $<<0.002)$ after 45 minutes. Patients in Group-I were also more oriented $(1.65 \pm 0.65)$ than those in Group-II (1.45 0.54$)$. In Group-I the patients were home ready by 60 mins., i.e. $97.5 \%$, whereas in Group-II it was $80 \%$ $(\mathrm{p}<0.05)$.

\section{CONCLUSION}

Thus, from our study we conclude that Propofol possesses many attractive feature as an inducing agent for day care surgery; more so when early movement of the patient is absolutely necessary. Rapid, clear headed recovery makes it a useful alternative to thiopentone in day care surgery.

\section{KEYWORDS}

Daycare Surgery, Anaesthetic Techniques, Recovery, Steward Scoring System.

HOW TO CITE THIS ARTICLE: Borgohain D, Bhattacharyya R, Bora J. Post anaesthetic recovery following day-care surgery: comparison of two anaesthetic techniques. J. Evolution Med. Dent. Sci. 2016;5(33):1777-1782, DOI: 10.14260/jemds/2016/419

\section{INTRODUCTION}

The growing demand for early discharge from hospital, consequent early return to work has resulted in the evolution of concept of "day care surgery." This has led to development of precise safe anaesthetic techniques and agents as well as a battery of tests of recovery.

Day care surgery, ambulatory or outpatient surgery can be defined as one in which the procedure is performed on a patient without overnight hospitalization either before or after surgery.

Financial or Other, Competing Interest: None.

Submission 08-03-2016, Peer Review 01-04-2016,

Acceptance 09-04-2016, Published 22-04-2016.

Corresponding Author:

Dr. Dhrubajyoti Borgohain,

Assistant Professor

Department of Anaesthesiology,

Assam Medical College,

Dibrugarh-786002, Assam

E-mail: dhruba_borgohain@yahoo.co.in

DOI: $10.14260 /$ jemds/2016/419
A part from being a cost effective quality health care, it offers certain advantages to the patient; the family, the hospital staff and community in particular such as reduces incidence of nosocomial/cross infection, minimizes psychological stress by their attachment to the family members, reduces financial burden, reduces waiting list for admission, etc. Unlike inpatient surgery, ambulatory surgery does not depend upon the availability of hospital beds. Day care anaesthesia centres around the four 'A's: Alertness, Analgesia, Alimentation and Ambulation. It is the quality of recovery from anaesthesia, which is of utmost importance in day stay surgical procedures.

Day care surgery presents unique challenges for the anaesthetists to produce a 'street fit' patient as soon as possible after the surgery with least complications, which can be achieved by both intravenous and inhalational techniques. Unfortunately, there is a trend of rising cost of the newer inhalation agents and serious concern has been raised regarding theatre pollution and green house effects apart from hazards to operating room personals. 
Reliable determination of recovery from anaesthesia is of absolute importance in day care surgery; as the patient though released to the care of the family, the moral and legal responsibilities remains with the anaesthetist and the surgeon. At the same time, it is difficult or rather impossible to predict when full mental faculties return. Not only early return of protective reflexes required, but return of co-ordination and motor skills are also desirable prior to "home readiness" after day care surgery.

Keeping all these views in mind and knowing fully our limitation and constraints; an endeavour is made to carry out the present study with the following aims and objectives:

- To assess the progress of recovery in patients undergoing day care surgery with two groups of intravenous anaesthetic agents employing different clinical recovery tests.

- To determine the optimum time taken and to determine the suitable agent necessary to achieve "home readiness."

\section{MATERIALS AND METHODS}

\section{Selection of Cases}

The study included patients of average intelligence of both sexes aged between 15 and 45 yrs. belonging to physical status ASA I and II, undergoing operative procedures less than 30 minutes in our institute over a period of two (2) years. A randomized double blind study was done amongst 80 patients scheduled for day care surgery such as D and E, McDonald suturing, Implant removal, Abscess drainage, Cystoscopy, etc. where two techniques were compared. A thorough patient's history was taken and a thorough physical examination was done. Minimal investigations like CBC, RBS, Serum Creatinine, BT, CT, Urine RE were done. Institutional Ethical Committee approval and written informed consent was duly taken. Details of the procedure including the recovery tests were explained to each and every patient and practised beforehand to make it fool proof.

We excluded ASA Grade III or IV patients, alcohol/drug abuse, $\mathrm{H} / \mathrm{O}$ allergic reactions to any of the drugs being used, patients with hypertension, DM, CAD and patients without an escort and those residing far away from the hospital.

\section{Plan of Study}

The patients were divided into two groups of 40 patients eachGroup I: Propofol (1\%) as the intravenous anaesthetic agent. Group II: Thiopentone (2.5\%) as the intravenous anaesthetic agent.

\section{Study Design}

Randomized double blind study. Method of randomization used was that of Opaque Envelope Method. Double blinding was done as the concerned patient and also the drug administrating doctor, both are blinded about the group of drug used.

\section{Procedure}

An IV line was started with 5\% Dextrose using an 18 gauge cannula in a forearm vein. Premedication was done with Inj. Ranitidine $50 \mathrm{mg}$, Inj. Ondansetron $4 \mathrm{mg}$ and Inj. Fentanyl 2 $\mathrm{mcg} / \mathrm{kg} \mathrm{IV}, 15 \mathrm{~min}$. before the start of the procedure. Patients were pre-oxygenated for $3 \mathrm{~min}$. using the Magill's circuit. Each patient was asked to count arithmetic numbers, while anaesthesia was induced slowly (Inj. made over 30 seconds) with either propofol (1\%) $2.5 \mathrm{mg} / \mathrm{kg}$ IV in Group I or thiopentone (2.5\%) $5 \mathrm{mg} / \mathrm{kg}$ IV in Group II; $1 \mathrm{~mL}$ of $2 \%$ lignocaine hydrochloride (Preservative free) was mixed with propofol to reduce the pain of injection.

- Induction time was noted as the interval from the start of injection to the cessation of counting of numbers/loss of eyelash reflex. During this period, the quality of anaesthesia was judged by observing various excitatory signs like hypertonus, spontaneous movement; twitching, tremor, cough, hiccup and laryngospasm and corrected if they occurred. Absence of these signs were regarded as excellent quality of anaesthesia.

- All patients were monitored with non-invasive BP device; heart rate, respiratory rate, pulse oximetry, ET $\mathrm{CO}_{2}$. Absence of purposeful movements and tachypnoea ( $R R>20 / \mathrm{min}$ ) was considered as optimal intraoperative analgesia.

- Maintenance was with oxygen $33 \%$, nitrous oxide $66 \%$ and sevoflurane $1-2 \%$ in spontaneously breathing patients using the Magill's circuit as it can be used for short procedures under 'spontaneous ventilation' where the duration of the procedure is less than $30 \mathrm{~min}$.

- The optimal surgical condition was defined as no movement or very minimal involuntary movement, which did not interfere with the course of the procedure.

- Incremental dose of $25-50 \%$ of the original bolus dose will be administered whenever there were signs of light anaesthesia (Judged by heart rate, $\mathrm{BP}$, respiratory rate and muscle tone).

- $\quad$ No muscle relaxant was used.

At the end of the surgical procedure, the inhalational agents were discontinued and patients oxygenated till they showed signs of recovery like spontaneous eye opening and respond to command. Total surgical time from incision to application of dressing was recorded. Also the total anaesthesia time was recorded from induction to discontinuation of anaesthetics. They were then transferred to the recovery room.

\section{Assessment of Recovery}

Recovery was assessed by using few standard scoring system as follows.

\section{Phase I Recovery}

(Return of consciousness and protective reflexes) - assessed by steward scoring system.[1] with the maximum score of six (6) and the lowest score being zero (0). The scores were evaluated observing the signs of recovery 5 mins. after cessation of anaesthesia on operation table; subsequently at 15 minutes interval in the recovery room till the score is $\geq 5$ up to the achievement of home readiness.

\section{Phase II Recovery}

(Return of cognitive and psychomotor function) assessed by various standard clinical tests which included

a. Orientation-Asking questions relating to patient's awareness status and awarded score ranging from 0-2.

b. Walk in a Straight Line: The patients were asked to walk along a straight line 5 meters long and then scored from $0-2$.

c. Romberg's Test 
The patient is asked to stand straight with eyes closed and both ankles opposed and accordingly scored from 0-2.

Phase II tests also comprised of maximum score of 6 with the lowest being zero. These tests are done in the recovery room in 15 mins. Interval until the patient's score is more or equal to 5 .

\section{Home Readiness}

Lastly, the patients were evaluated for home readiness (every $30 \mathrm{~min}$.) by observing the following clinical parameters

- Stable vital signs $>30$ mins.

- Orientated to time, place and person.

- Ability to walk without assistance.

- No active bleeding/oozing.

- No headache/nausea/vomiting >30 mins.

- Ability to void.

- Ability to tolerate oral fluid.

- Ability to dress by oneself.

- Pain controllable with oral analgesics.

- Accompaniment with a responsible adult to escort and stay at home.

If the patient can achieve all the above criteria, then recovery is assumed to be complete - score 2 .

If 4-6 criterias are fulfilled - partial recovery - score 1.

If $\leq 3$ criterias are fulfilled - no recovery - score 0 .

On complete recovery, the patients were discharged with full verbal and written instructions.

\section{RESULTS AND OBSERVATIONS}

Data management was done with the help of excel spreadsheet. The different variables were evaluated by mean and standard deviation. For comparing two groups, paired ' $\mathrm{t}$ ' test was applied and a $\mathrm{p}$ value of $<0.05$ was considered significant.

The maximum number of patients belonged to the age group 15-25 years (55\%) irrespective of the gender in both the groups. The lowest number of patients were seen in the age group 36-45 years. There was no statistically significant difference among the group (Table 1 and 2).

No statistically significant difference $(\mathrm{p}>0.05)$ was seen among the two groups in respect to duration of anaesthesia or surgery. However, mean total dose requirement in Group II patients were more than that in Group I patients and their difference was highly significant statically $(\mathrm{p}<0.001)$ [Table 3]. However, in the study, none of the cases in either groups needed any incremental dose during the procedure. When comparing the induction time in both the study groups, no statically significant difference was noted ( $>>0.05)$ [Table 4].

When comparing the quality of anaesthesia, it was excellent in $57.5 \%$ in Group I as compared to $45 \%$ in Group II; Good in $42.5 \%$ in Group I as compared to $50 \%$ in Group II. No case of poor quality of anaesthesia was seen in Group I, while 2 cases had poor quality of anaesthesia in Group II (5\%) [Table 5]. Incidence of pain during injection was more in Group I, while incidence of PONV was significantly greater in Group II. The incidence of hypotension was seen to be much more in Group I than in Group II. Other side effects were comparable in the study groups [Table 6].
After 5 minutes of cessation of anaesthesia, patients in Group I attained much higher score as compared to Group II $(\mathrm{p}<0.001)$ as assessed by the "Steward scoring system" [Table 7].

It was observed that after 15 minutes, patients in Group I could attain a mean score of $5.75 \pm 0.48$ as compared to that in Group II, where they attained a score of $4.5 \pm 0.49$. Statistically, this was found to very highly significant [Table 8].

Patients in Group I were also more oriented $(1.65 \pm 0.65)$ than those in Group II (1.45 \pm 0.54$)$; However, this different was only slightly significant. [Table-8] The above table shows that by 30 minutes patients in both the Groups attained almost comparable score in the Steward scoring system and orientation. However, walking along a straight line and Romberg's test was found better in Group I than in Group II and this difference was highly significant $(\mathrm{p}<0.001)$ [ Table 9]. It was observed that patients in both the groups attained full score of Steward scoring system and orientation.

However, scores attained by the patients in both groups to perform Romberg's test and walking along a straight line were not significant. More number of patients were "Home ready" in Group I than in Group II ( $\mathrm{p}<0.002)$ after 45 minutes. [Table 10] The score of both the groups in walking along a straight line. Romberg's tests were comparable after 60 minutes. However, there was a moderate difference in patients who are "Home ready" in relations to statistical data, which is insignificant [Table 11].

The scores were comparable in both the groups after 90 (Ninety) minutes, but while all the patients in Group I were "home ready." A small number of patients in Group II had to be further observed and evaluated to be fit for discharge because they could not achieve the full score for home readiness. [Table 12] All the patients were fit for discharge after 120 minutes in both the study groups. None of the patients under the two study groups required indoor admission, as they fulfilled postoperative discharge criteria within two hours of surgery and anaesthesia. Patients were advised to be attended by a responsible adult for at least 24 hours; not to drive or operate any machinery. They were discharged after an informed consent duly signed by the attendant. It also advised to contact the attending doctor in case of any untoward complications. [Table 13].

All the patients were fit for discharge by 90 minutes in Group I, while Group II patients had taken 120 minutes to attain the home readiness score [Table 14, 15, 16, 17, 18], which signifies that recovery with Group I (Propofol) was better than that of Group II (Thiopentone).

\begin{tabular}{|l|c|c|}
\hline \multicolumn{1}{|c|}{ Characteristics } & Group - I & Group - II \\
\hline Number of patients & 40 & 40 \\
Mean age (In years) & $25.95 \pm 9.62$ & $24.85 \pm 6.64$ \\
Mean weight (In Kgs) & $47.57 \pm 11.54$ & $46.62 \pm 10.47$ \\
Sex (Male:Female) & $30: 10$ & $30: 10$ \\
Physical status (I:II) & $37: 3$ & $37: 3$ \\
\hline \multicolumn{2}{|c|}{ Table 1: Demographic Data } \\
of the Patients Under Study
\end{tabular}




\begin{tabular}{|c|c|c|c|c|c|c|c|c|}
\hline \multirow{3}{*}{ Age Groups } & \multicolumn{4}{|c|}{ Group - I } & \multicolumn{4}{|c|}{ Group - II } \\
\hline & \multicolumn{2}{|c|}{ Total } & \multirow{2}{*}{ Male } & \multirow{2}{*}{ Female } & \multicolumn{2}{|c|}{ Total } & \multirow{2}{*}{ Male } & \multirow{2}{*}{ Female } \\
\hline & No. & $\%$ & & & No. & $\%$ & & \\
\hline $15-25$ & 20 & 50.0 & 16 & 4 & 24 & 60.0 & 19 & 5 \\
\hline $26-35$ & 13 & 32.5 & 7 & 6 & 12 & 30.0 & 8 & 4 \\
\hline $36-45$ & 7 & 17.5 & 7 & 0 & 4 & 10.0 & 3 & 1 \\
\hline
\end{tabular}

\begin{tabular}{|c|c|c|c|}
\hline & Group - I & Group - II & Comparison \\
\hline Mean duration of surgery (min.) & $6.50 \pm 3.98$ & $6.57 \pm 3.55$ & $\mathrm{P}<0.05$ \\
Mean duration of anaesthesia (min.) & $7.50 \pm 3.96$ & $8.02 \pm 3.98$ & $\mathrm{p}>0.05$ \\
Total Dose & $128.75 \pm 36.21$ & $246.50 \pm 68.52$ & $\mathrm{p}<0.001$ \\
\hline \multicolumn{2}{|c|}{ Table 3: Anaesthetic Detail of the Study Group (Mean \pm SD) } \\
\hline
\end{tabular}

\begin{tabular}{|c|c|c|}
\hline Groups & Induction Time (Sec.) & Comparison \\
\hline Group-I & $30.10 \pm 5.15$ & $\mathrm{~T}=1.04, \mathrm{df}=78$ \\
Group-II & $28.95 \pm 4.78$ & $\mathrm{p}>0.05$ \\
\hline \multicolumn{3}{|c|}{ Table 4: Onset of Induction in the } \\
Study Groups (Mean \pm SD) \\
\hline
\end{tabular}

\begin{tabular}{|c|c|c|c|c|c|}
\hline Quality of & \multicolumn{2}{|c|}{ Group-I } & \multicolumn{2}{c|}{ Group-II } & \multirow{2}{*}{ Comparison } \\
\cline { 2 - 6 } Anaesthesia & No. & $\%$ & No. & $\%$ & \\
\hline Excellent & 23 & 57.5 & 18 & 45.0 & $\mathrm{X}^{2}=2.84$ \\
Good & 17 & 42.5 & 20 & 50.0 & Df $=2$ \\
Poor & 0 & 0 & 2 & 5.0 & $\mathrm{p}>0.05$ \\
\hline Table 5: Quality of Anaesthesia in the Study Groups \\
\hline
\end{tabular}

\begin{tabular}{|c|c|c|c|c|}
\hline \multirow{2}{*}{ Side Effects } & \multicolumn{2}{|c|}{ Group-I } & \multicolumn{2}{c|}{ Group-II } \\
\cline { 2 - 5 } & No. & \% & No. & $\%$ \\
\hline Apnoea & 16 & 40.0 & 14 & 35.0 \\
Hypotension & 18 & 45.0 & 5 & 12.5 \\
Tachycardia & 0 & 0 & 1 & 2.5 \\
Bradycardia & 0 & 0 & 3 & 7.5 \\
Pain on injection & 10 & 25.0 & 0 & 0 \\
Hypertonus & 2 & 5.0 & 3 & 7.5 \\
Spontaneous movement & 10 & 25.0 & 10 & 25.0 \\
Cough/Hiccup & 0 & 0 & 1 & 2.5 \\
Nausea/Vomiting & 0 & 0 & 9 & 22.5 \\
Indoor admission & 0 & 0 & 0 & 0 \\
\hline Table 6: Incidence of Side Effects in the Study Groups \\
\hline
\end{tabular}

\begin{tabular}{|c|c|c|c|}
\hline Observations & Group-I & Group-II & Comparison \\
\hline $\begin{array}{l}\text { Steward } \\
\text { Scoring }\end{array}$ & $3.52 \pm 0.97$ & $1.97 \pm 0.96$ & $\begin{array}{c}\mathrm{t}=5.16 \\
\mathrm{df}=78 \\
\mathrm{p}<0.001\end{array}$ \\
\hline \multicolumn{4}{|c|}{$\begin{array}{c}\text { Table 7: Observations Made at } 5 \text { (Five) Minutes After } \\
\text { Termination of Anaesthesia }\end{array}$} \\
\hline
\end{tabular}

\begin{tabular}{|c|c|c|c|}
\hline Observations & Group-I & Group-II & Comparison \\
\hline $\begin{array}{c}\text { Steward } \\
\text { scoring }\end{array}$ & $5.75 \pm 0.48$ & $4.5 \pm 0.49$ & $\begin{array}{c}\mathrm{T}=12.5 \\
\mathrm{P}<0.001\end{array}$ \\
\hline Orientation & $1.65 \pm 0.65$ & $1.45 \pm 0.54$ & $\begin{array}{c}\mathrm{T}=1.5 \\
\mathrm{P}<0.001\end{array}$ \\
\hline \multicolumn{3}{|c|}{ Table 8: Observations Made at 15 (Fifteen) Minutes } \\
After Termination of Anaesthesia
\end{tabular}

\begin{tabular}{|c|c|c|c|}
\hline Observations & Group-I & Group-II & Comparison \\
\hline Steward scoring & $5.97 \pm 0.46$ & $5.95 \pm 0.85$ & $\begin{array}{c}\mathrm{T}=1.11, \\
\mathrm{P}<0.05\end{array}$ \\
\hline Orientation & $1.97 \pm 0.15$ & $1.95 \pm 0.21$ & $\begin{array}{c}\mathrm{T}=0.5 \\
\mathrm{P}<0.05\end{array}$ \\
\hline $\begin{array}{c}\text { Walk along a } \\
\text { straight line }\end{array}$ & $1.8 \pm 0.51$ & $1.3 \pm 0.63$ & $\begin{array}{c}\mathrm{T}=4.16, \\
\mathrm{P}<0.001\end{array}$ \\
\hline Romberg's test & $1.8 \pm 0.41$ & $1.3 \pm 0.61$ & $\begin{array}{c}\mathrm{T}=5.0 \\
\mathrm{P}<0.001\end{array}$ \\
\hline \multicolumn{3}{|c|}{ Table 9: Observations After 30 (Thirty) Minutes } \\
\hline
\end{tabular}

\begin{tabular}{|c|c|c|c|}
\hline Observations & Group-I & Group-II & Comparison \\
\hline Steward scoring & $6 \pm 0$ & $6 \pm 0$ & \\
\hline Orientation & $2 \pm 0$ & $2 \pm 0$ & \\
\hline $\begin{array}{c}\text { Walk along a } \\
\text { straight line }\end{array}$ & $1.92 \pm 0.26$ & $1.77 \pm 0.47$ & $\begin{array}{c}\mathrm{T}=2.5 \\
\mathrm{P}>0.01 \\
<0.02\end{array}$ \\
\hline Romberg's test & $1.97 \pm 0.15$ & $1.87 \pm 0.38$ & $\begin{array}{c}\mathrm{T}=1.68 \\
\mathrm{P}<0.05\end{array}$ \\
\hline Home readiness & $1.7 \pm 0.67$ & $1.1 \pm 0.7$ & $\begin{array}{c}\mathrm{t}-4.0 \\
\mathrm{p}<0.001\end{array}$ \\
\hline \multicolumn{3}{|c|}{ Table 10: Observations After 45 (Forty-Five) Minutes } \\
\hline
\end{tabular}

\begin{tabular}{|c|c|c|c|}
\hline Observations & Group-I & Group-II & Comparison \\
\hline $\begin{array}{c}\text { Walk along a } \\
\text { straight line }\end{array}$ & $2 \pm 0$ & $1.92 \pm 0.26$ & $\begin{array}{c}\mathrm{T}=1.87 \\
\mathrm{P}<0.05\end{array}$ \\
\hline Romberg's test & $2 \pm 0$ & $1.925 \pm 0.26$ & $\begin{array}{c}\mathrm{T}=1.87 \\
\mathrm{P}<0.05\end{array}$ \\
\hline $\begin{array}{c}\text { Home } \\
\text { readiness }\end{array}$ & $1.95 \pm 0.31$ & $1.75 \pm 0.53$ & $\begin{array}{c}\mathrm{T}=2.22 \\
\mathrm{p}<0.05\end{array}$ \\
\hline \multicolumn{3}{|c|}{ Table 11: Observations After 60 (Sixty) Minutes } \\
\hline
\end{tabular}

\begin{tabular}{|c|c|c|c|}
\hline Observations & $\begin{array}{c}\text { Group } \\
-I\end{array}$ & Group-II & Comparison \\
\hline $\begin{array}{c}\text { Walk along a } \\
\text { straight line }\end{array}$ & $2 \pm 0$ & $1.975 \pm 0.33$ & $\begin{array}{c}\mathrm{T}=0.33 \\
\mathrm{P}<0.05\end{array}$ \\
\hline Romberg's test & $2 \pm 0$ & $2 \pm 0$ & \\
\hline Home readiness & $2 \pm 0$ & $1.95 \pm 0.43$ & $\begin{array}{c}\mathrm{T}=0.83 \\
\mathrm{p}<0.05\end{array}$ \\
\hline \multicolumn{3}{|c|}{ Table 12: Observations After 90 (Ninety) Minutes } \\
\hline
\end{tabular}

\begin{tabular}{|c|c|c|l|}
\hline Observations & $\begin{array}{c}\text { Group- } \\
\text { I }\end{array}$ & $\begin{array}{c}\text { Group- } \\
\text { II }\end{array}$ & Comparison \\
\hline Home readiness & $2 \pm 0$ & $2 \pm 0$ & \\
\hline \multicolumn{3}{|c|}{ Table 13: Observations After 120 } \\
(One-Hundred and Twenty) Minutes \\
\hline
\end{tabular}




\begin{tabular}{|c|c|c|c|c|c|c|c|c|c|c|c|c|c|c|c|c|}
\hline \multirow{2}{*}{ Study Groups } & \multirow{2}{*}{ Age Groups } & \multicolumn{3}{|c|}{5 Min. } & \multicolumn{3}{|c|}{15 Min. } & \multicolumn{3}{|c|}{30 Min. } & \multicolumn{3}{|c|}{45 Min. } & \multicolumn{3}{|c|}{$60 \mathrm{Min}}$. \\
\hline & & M & $\mathbf{F}$ & $\mathbf{T}$ & $\mathbf{M}$ & $\mathbf{F}$ & $\mathbf{T}$ & $\mathbf{M}$ & $\mathbf{F}$ & $\mathbf{T}$ & $\mathbf{M}$ & $\mathbf{F}$ & $\mathbf{T}$ & $\mathbf{M}$ & $\mathbf{F}$ & $\mathbf{T}$ \\
\hline \multirow{3}{*}{ I } & $15-25$ & 3 & 1 & 4 & 15 & 4 & 19 & 16 & 4 & 20 & 16 & 4 & 20 & 16 & 4 & 20 \\
\hline & $26-35$ & 0 & 0 & 0 & 6 & 6 & 12 & 7 & 6 & 13 & 7 & 6 & 13 & 7 & 6 & 13 \\
\hline & $36-45$ & 3 & 0 & 3 & 7 & 0 & 7 & 7 & 0 & 7 & 7 & 0 & 7 & 7 & 0 & 7 \\
\hline \multirow{3}{*}{ II } & $15-25$ & 0 & 0 & 0 & 12 & 1 & 13 & 19 & 5 & 24 & 19 & 5 & 24 & 19 & 5 & 24 \\
\hline & $26-35$ & 0 & 0 & 0 & 4 & 0 & 4 & 8 & 4 & 12 & 8 & 4 & 12 & 8 & 4 & 12 \\
\hline & $36-45$ & 0 & 0 & 0 & 3 & 0 & 3 & 3 & 1 & 4 & 3 & 1 & 4 & 3 & 1 & 4 \\
\hline & $\begin{array}{r}\text { Table } 14 \\
\text { St }\end{array}$ & & & & $f$ & & & & & & $\begin{array}{l}\text { tta } \\
\text { sia }\end{array}$ & & & & & \\
\hline
\end{tabular}

\begin{tabular}{|c|c|c|c|c|c|c|c|c|c|c|c|c|c|}
\hline \multirow{2}{*}{ Study Groups } & \multirow{2}{*}{ Age Groups } & \multicolumn{3}{|c|}{30 Min. } & \multicolumn{3}{|c|}{45 Min. } & \multicolumn{3}{|c|}{60 Min. } & \multicolumn{3}{|c|}{90 Min. } \\
\hline & & $\mathbf{M}$ & $\mathbf{F}$ & $\mathbf{T}$ & $\mathbf{M}$ & $\mathbf{F}$ & $\mathbf{T}$ & $\mathbf{M}$ & $\mathbf{F}$ & $\mathbf{T}$ & $\mathbf{M}$ & $\mathbf{F}$ & $\mathbf{T}$ \\
\hline \multirow{3}{*}{ I } & $15-25$ & 14 & 4 & 18 & 15 & 4 & 19 & 16 & 4 & 20 & 16 & 4 & 20 \\
\hline & $26-35$ & 4 & 5 & 9 & 5 & 6 & 11 & 7 & 6 & 13 & 7 & 6 & 13 \\
\hline & $36-45$ & 7 & 0 & 7 & 7 & 0 & 7 & 7 & 0 & 7 & 7 & 0 & 7 \\
\hline \multirow{3}{*}{ II } & $15-25$ & 8 & 0 & 8 & 17 & 2 & 19 & 18 & 4 & 22 & 18 & 5 & 23 \\
\hline & $26-35$ & 4 & 1 & 5 & 7 & 3 & 10 & 8 & 3 & 11 & 8 & 4 & 12 \\
\hline & $36-45$ & 2 & 0 & 2 & 3 & 1 & 4 & 3 & 1 & 4 & 3 & 1 & 4 \\
\hline \multicolumn{14}{|c|}{$\begin{array}{l}\text { Table 15: Number of Patients in Both the Groups Who Could Walk in a } \\
\text { Straight Line at Various Time Intervals after Anaesthesia }\end{array}$} \\
\hline
\end{tabular}

\begin{tabular}{|c|c|c|c|c|c|c|c|c|c|c|c|c|c|}
\hline \multirow{2}{*}{ Study Groups } & \multirow{2}{*}{ Age Groups } & \multicolumn{3}{|c|}{30 Min. } & \multicolumn{3}{|c|}{45 Min. } & \multicolumn{3}{|c|}{$60 \mathrm{Min}$} & \multicolumn{3}{|c|}{90 Min. } \\
\hline & & $\mathbf{M}$ & $\mathbf{F}$ & $T$ & $\mathbf{M}$ & $\mathbf{F}$ & $\mathbf{T}$ & $\mathbf{M}$ & $\mathbf{F}$ & $\mathbf{T}$ & $\mathbf{M}$ & $\mathbf{F}$ & $\mathbf{T}$ \\
\hline \multirow{3}{*}{ I } & $15-25$ & 14 & 3 & 17 & 16 & 4 & 20 & 16 & 4 & 20 & 16 & 4 & 20 \\
\hline & $26-35$ & 4 & 5 & 9 & 6 & 6 & 12 & 7 & 6 & 13 & 7 & 6 & 13 \\
\hline & $36-45$ & 7 & 0 & 7 & 7 & 0 & 7 & 7 & 0 & 7 & 7 & 0 & 7 \\
\hline \multirow{3}{*}{ II } & $15-25$ & 10 & 0 & 10 & 16 & 4 & 20 & 18 & 4 & 22 & 18 & 5 & 23 \\
\hline & $26-35$ & 3 & 1 & 4 & 7 & 3 & 10 & 8 & 3 & 11 & 8 & 4 & 12 \\
\hline & $36-45$ & 2 & 0 & 2 & 3 & 0 & 3 & 3 & 1 & 4 & 3 & 1 & 4 \\
\hline \multicolumn{14}{|c|}{$\begin{array}{l}\text { Table 16: Number of Patients in Both the Study Groups who Could Correctly } \\
\text { Perform Romberg's Test at Various Time Intervals after Anaesthesia }\end{array}$} \\
\hline
\end{tabular}

\begin{tabular}{|c|c|c|c|c|c|c|c|c|c|c|c|c|c|}
\hline \multirow{2}{*}{ Study Groups } & \multirow{2}{*}{ Age Groups } & \multicolumn{3}{|c|}{45 Min. } & \multicolumn{3}{|c|}{60 Min. } & \multicolumn{3}{|c|}{90 Min. } & \multicolumn{3}{|c|}{120 Min. } \\
\hline & & $\mathbf{M}$ & $\mathbf{F}$ & $\mathbf{T}$ & $\mathbf{M}$ & $\mathbf{F}$ & $\mathbf{T}$ & $\mathbf{M}$ & $\mathbf{F}$ & $\mathbf{T}$ & $\mathbf{M}$ & $\mathbf{F}$ & $\mathbf{T}$ \\
\hline \multirow{3}{*}{ I } & $15-25$ & 15 & 3 & 18 & 16 & 4 & 20 & 16 & 4 & 20 & 16 & 4 & 20 \\
\hline & $26-35$ & 3 & 5 & 8 & 6 & 6 & 12 & 7 & 6 & 13 & 7 & 6 & 13 \\
\hline & $36-45$ & 7 & 0 & 7 & 7 & 0 & 7 & 7 & 0 & 7 & 7 & 0 & 7 \\
\hline \multirow{3}{*}{ II } & $15-25$ & 7 & 0 & 7 & 15 & 4 & 19 & 18 & 5 & 23 & 18 & 5 & 23 \\
\hline & $26-35$ & 2 & 1 & 3 & 7 & 2 & 9 & 8 & 4 & 12 & 8 & 4 & 12 \\
\hline & $36-45$ & 2 & 0 & 2 & 3 & 0 & 3 & 3 & 1 & 4 & 3 & 1 & 4 \\
\hline \multicolumn{14}{|c|}{$\begin{array}{l}\text { Table 17: Number of Patients in Both the Groups who Could Be } \\
\text { Considered "Home Ready" At Various Time Intervals after Anaesthesia }\end{array}$} \\
\hline
\end{tabular}

\begin{tabular}{|c|c|c|c|c|c|c|c|c|}
\hline Study Groups & Observations & 5 Min. & 15 Min. & 30 Min. & 45 Min. & 60 Min. & 90 Min. & 120 Min. \\
\hline \multirow[t]{5}{*}{ 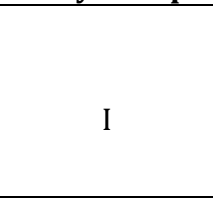 } & Steward scoring & 17.5 & 95 & 100 & 100 & 100 & 100 & 100 \\
\hline & Orientation & & 72.5 & 97.5 & 100 & 100 & 100 & 100 \\
\hline & Walk in a straight line & & & 85 & 92.5 & 100 & 100 & 100 \\
\hline & Romberg's test & & & & 85 & 97.5 & 100 & 100 \\
\hline & Home readiness & & & & 82.5 & 97.5 & 100 & 100 \\
\hline \multirow{5}{*}{ II } & Steward scoring & 0 & 50 & 97.5 & 100 & 100 & 100 & 100 \\
\hline & Orientation & & 47.5 & 95 & 100 & 100 & 100 & 100 \\
\hline & Walk in a straight line & & & 37.5 & 82.5 & 92.5 & 100 & 100 \\
\hline & Romberg's test & & & 40 & 82.5 & 92.5 & 100 & 100 \\
\hline & Home readiness & & & & 30 & 80 & 97.5 & 100 \\
\hline \multicolumn{9}{|c|}{$\begin{array}{l}\text { Table 18: Number of Patients (In Percentages) who had Attained Full } \\
\text { Recovery Test Score at Various Time Intervals after Termination Anaesthesia }\end{array}$} \\
\hline
\end{tabular}




\section{DISCUSSION}

Day surgery is defined as planned investigations or procedures on patients who are admitted and discharged home on the day of their surgery, but require some facilities and time for recovery. The definition of a day care patient is "a person attending as a non-resident patient for investigation, therapeutic tests, operation or other treatment who required preparation, recovery or both involving the provision of services and accommodation."

As propofol and thiopentone do not have any analgesic property, we had used Fentanyl in low dose for analgesia (Bajwa and Bajwa, 2010).[2] Fentanyl does not unduly delay recovery and provides early post-operative analgesia. Ghabash M used fentanyl to depress the excitatory effects of Propofol to provide cardiovascular stability, deepen the plane of anaesthesia and decrease the awareness (Ghabash et al. 1990).[3]

In the present study, the progress of recovery was assessed in the light of 'Steward scoring system' and later on by various clinical tests. Post-anaesthetic discharge criteria were applied to assess "Home readiness."

"Clinical Tests" were performed with the help of "Romberg's Test" and "Walking in straight line." These tests were performed only after the attainment of Steward score $\geq 5$. [4] [5]

At 30 minutes, there was gross difference in attainment of score in these tests between the two groups. However, the scores started to be equal once 45 minutes interval had been crossed. By 60-90 minutes; patients both the groups attained comparable scores. In our study, no statistically significant difference ( $p>0.05$ ) was seen among the two groups in respect to duration of anaesthesia or surgery. However, mean total dose requirement in Group II patients were more than that in Group I patients and their difference was highly significant statically $(\mathrm{p}<0.001)$ [Table 3].

Home readiness was assessed by applying the postanaesthetic discharge criteria.[6]

In our study, 97.5\% of patients in Group I were fit for discharge (home ready) at 60 minutes as compared to only $80 \%$ of patients in Group II. The scores obtained by Group I patients after 60 minutes were $1.95 \pm 0.31$, while that by Group II patients were $1.75 \pm 0.53$. This difference was found to be moderately significant, was minimal after 90 minutes ( $P>0.05)$. At 90 minutes, all patients in Group I was home ready (score 2), while patients in Group II attained a score $1.95 \pm 0.43$. All the patients were fit for discharge by 90 minutes in Group I, while Group II patients had taken 120 minutes to attain the home readiness score [Table 14, 15, 16, 17, 18], which signifies that recovery with Group I (Propofol) was better than that of Group II (Thiopentone) that is comparable to studies by McKenzie N and Grant IS.[7] and Marudhachalam KS et al.[8] Pavlin et al. Also reported that GA with newer anaesthetic drugs allowed an earlier discharge as compared with spinal or epidural anaesthesia. [9]

\section{CONCLUSIONS}

From our Study, we could Conclude that

- Steward scoring system appears to be the earliest predictor of recovery with prompt return of protective reflexes, but not home readiness.

- Orientation of time, place and person is essential for early recovery.

- Tests for psychomotor coordination appears to be most sensitive index for assessment of "Home readiness." In this study we may conclude that in Group I the patients were home ready by 60 mins., i.e. $97.5 \%$, whereas in Group II it was $80 \%(\mathrm{p}<0.05)$.

- Propofol possess many attractive feature as an inducing agent for day care surgery; more so when early movement of the patient is absolutely necessary. Rapid, clear headed recovery may make it a useful alternative to thiopentone in day care surgery. Otherwise, no marked advantage were observed over of the conventional agent thiopentone. Most of the features of the two drugs were comparable.

\section{REFERENCES}

1. Steward DJ. A simplified scoring system for the post operative recovery room canad. Anaesth Soc Journal 1995;22(1):111-3.

2. Bajwa SJS, Bajwa SK. Comparison of two drug combinations in TIVA : propofol-ketamine and propofolfentanyl. Saudi Journal of Anaesthesia 2010;4(2):72-9.

3. Ghabash M, Matta M, Kehhaleh J. Depression of excitatory effects of propofol induction by fentanyl. Middle East Journal of Anaesthesia 1996;13(4):419-25.

4. Vickers MD. The measurement of recovery from anaesthesia. British Journal of Anaesthesia 1965;37(5):296-302.

5. Kortilla K. Recovery from day care anaesthesia. Ballier 's clinical anaesthesiology 1990;4:713.

6. Kortilla K. Practical discharge criteria. Problems in anaesthesia 1988;2:144-151.

7. McKenzie N, Grant IS. Comparision of new emulsion formulation of propofol with methohexitone and thiopentone for induction of anaesthesia in day cases. $\mathrm{Br}$ J Anaes 1985;57(8):725-31.

8. Marudhachalam KS, Chari P. Comparision of propofol and thiopentone for induction and recovery of anaesthesia in children. J Anaesth Clinical Pharmacology 1996;12:185.

9. Janet D Pavlin, Rapp SE, Polissar NL. Factors affecting discharge time in adult outpatients. Anaesthesia and Analgesia 1998;87(4):816-26. 